\title{
Anesthetic protocol for videolaparoscopic surgery in rabbits ${ }^{1}$
}

\author{
Protocolo anestésico para cirurgia videolaparoscópica em coelhos
}

\author{
Rosi Pereira BalbinottoI, Manoel Roberto Maciel Trindade ${ }^{\mathrm{II}}$, Fabíola Schons Meyer ${ }^{\mathrm{III}}$, Ana Lucia Letti Muller ${ }^{\mathrm{IV}}$, Arlindo da Rosa \\ $\mathrm{Jr}^{\mathrm{V}}$, André Gorgen Nunes ${ }^{\mathrm{VI}}$, Rodrigo da Silva ${ }^{\mathrm{VI}}$ \\ ${ }^{1} \mathrm{MD}$, Gynecologist and Obstetrician, Hospital de Clínicas de Porto Alegre (HCPA), Porto Alegre-RS, Brazil. \\ ${ }^{\text {II }} \mathrm{PhD}$, Associate Professor, Department of Surgery, UFRS and Head, Division of Digestive Surgery, HCPA, Porto Alegre-RS, Brazil. \\ III Veterinarian, Animal Experimentation Unit Research, HCPA, Porto Alegre-RS, Brazil. \\ ${ }^{\text {IV }} \mathrm{PhD}$, Gynecologist and Obstetrician, HCPA, Porto Alegre-RS, Brazil. \\ ${ }^{v}$ M.Sc in Surgery, Gynecologist and Obstetrician, Porto Alegre-RS, Brazil. \\ ${ }^{\mathrm{VI}}$ Graduate Student, UFRS, Porto Alegre-RS, Brazil.
}

\begin{abstract}
Purpose: To describe the anesthetic protocol and the intubation technique without visualizing the trachea in rabbits, in order to enable the videolaparoscopic surgical procedure. Methods: The experiment was performed on 33 female rabbits (Oryctolagus cuniculus), aged from 5 to 7 months. It consisted of general anesthesia and endotracheal intubation by manual palpation of the trachea of the rabbits, without using the laryngoscope, orally, for later videolaparoscopic surgical access to the abdominal cavity. Results: The mean values and standard deviation of vital parameters of the animals were $223.8 \pm 15.61$ beats per minute for heart rate; $35 \pm 9$ movements per minute for respiratory rate; $96.94 \pm 0.99 \%$ of oxymetry and $42.82 \pm 4.02 \mathrm{mmHg}$ for capnometry; $16.7 \pm 4.3$ minutes for pneumoperitoneum (duration of surgery) and 1 hour and $14 \pm 8.52$ minutes for time of observation (from induction to recovery from anesthesia). All animals were intubated in at most three attempts. No animals were lost after the introduction of this anesthetic technique. Conclusion: This protocol proved adequate, safe and easy to perform, on rabbits submitted to videolaparoscopic surgery.
\end{abstract}

Key words: Anesthesia. Laparoscopy. Surgery. Animal Experimentation. Rabbits.

\section{RESUMO}

Objetivo: Descrever o protocolo anestésico e a técnica de intubação sem visualização da traqueia em coelhos, para viabilização de procedimento cirúrgico videolaparoscópico. Métodos: O experimento foi realizado em 33 coelhas (Oryctolagus cuniculus), com idade entre 5 e 7 meses. Consistiu de anestesia geral e intubação endotraqueal por meio de palpação manual da traquéia das coelhas, sem o uso de laringoscópio, pela via oral, para posterior acesso cirúrgico videolaparoscópico da cavidade abdominal. Resultados: Os valores médios e desvio padrão dos parâmetros vitais dos animais foram de 223,8 $\pm 15,61$ batimentos por minuto para freqüência cardíaca; $35 \pm 9$ movimentos por minuto para frequência respiratória; $96,94 \pm 0,99 \%$ de oximetria e $42,82 \pm 4,02 \mathrm{mmHg}$ para capnometria; $16,7 \pm 4,3$ minutos para o pneumoperitônio (tempo de cirurgia) e 1 hora e 14 8,52 minutos para o tempo de observação (desde a indução até a recuperação anestésica). Todos os animais foram intubados em, no máximo, três tentativas. Não houve perda de animais após a introdução dessa técnica anestésica. Conclusão: Este protocolo mostrou-se adequado, seguro e de fácil realização, para a aplicação em coelhos submetidos à cirurgia videolaparoscópica.

Descritores: Anestesia. Laparoscopia. Cirurgia. Experimentação Animal. Coelhos.

${ }^{1}$ Research performed at Animal Experimentation Unit Research Center, Federal University of Rio Grande do Sul (UFRS), Porto Alegre-RS, Brazil.

\section{Introduction}

Rabbits are widely used for research in experimental surgery. This is due to the fact that they are low cost, small sized animals, with easy venous access, and because they have a number of anatomical and physiological characteristics that are useful for research ${ }^{1}$.
Often rabbits are considered difficult to anesthetize, partly due to problems in endotracheal intubation, since the shape of the oral cavity of these animals prevents visualization of the larynx, and also because these animals are highly susceptible to respiratory arrest, when the anesthetic procedure has been implemented ${ }^{2}$. A few authors use tracheostomy to ventilate rabbits during the anesthetic procedure ${ }^{3}$; others suggest that the 
procedure be performed viewing the larynx through fiberoptics ${ }^{4}$. Endotracheal intubation is difficult in these animals because of the long distance between the incisors and the epiglottis, the extremely sharp teeth and small size of the oral cavity, besides the occurrence of laryngeal spasm ${ }^{1}$. The highest risk in the rabbit intubation process is laryngeal trauma with consequent edema of the glottis, which may require euthanizing the animal ${ }^{5}$.

Besides difficulties in intubation, other factors affect the response of a rabbit to anesthetics. It can be said that a dose considered sufficient to kill an animal may weakly affect another. The specific factors that influence this response are: sex, age, strain, body weight, percentage of body fat, nutritional status and health, gastrointestinal content, time of day, genetic variations and respiratory and metabolic rhythms ${ }^{1}$.

Therefore, good anesthetic equipment, besides the anesthetist using the precise doses, increase the safety of anesthesia.

The purpose of this study is to propose a protocol to anesthetize rabbits, characterized by safe induction of anesthesia and by an endotracheal intubation technique without visualizing the trachea, easy to use and with a low risk of trauma to the animal, in order to allow a videolaparoscopic surgical procedure.

\section{Methods}

An experimental study was performed. The variables controlled were time of pneumoperitoneum, anesthetic parameters (heart rate, respiratory rate, oxymetry, capnometry, time of anesthetic observation) and anesthetic complications.

This study is part of a project approved by the Ethics and Research Committee of the Research and Graduate Group at Clinics Hospital of de Porto Alegre, under number 06-531.

Thirty-three healthy, non-pregnant adult white rabbits (Oryctolagus cuniculus), of the New Zealand breed (aged 5 to 7 months) were used. The animals were accommodated in individual cages, specifically built for rabbits, in a controlled environment, according to a local standard that follows the recommendations of the Guide for the Care and Use of Laboratory Animals.

All the animals were submitted to a mandatory quarantine, lasting 6 days, and identified by a tattoo on the right ear.

On the day of surgery, the rabbits were fasted for 3 hours preoperatively.

Acepromazine $(0.25 \mathrm{mg} / \mathrm{kg})^{7,8}$, midazolam $(1 \mathrm{mg} / \mathrm{kg})$ and meperidine $(5 \mathrm{mg} / \mathrm{kg})$ were administered intramuscularly as preanesthetic medication for sedation and analgesia ${ }^{1}$. After 10 minutes, they were shaved as required for the surgical procedure and access to the marginal vein of the ear was performed for fluid therapy $(5 \mathrm{ml} / \mathrm{kg} / \mathrm{h}$ of sodium chloride $0.9 \%)$. Before anesthetic induction, $100 \%$ oxygen therapy was given for 5 minutes.

The induction of general anesthesia was performed with Isoflurane $5 \%{ }^{1,2}$, using a face mask (Figure 1). Induction was interrupted if the rabbit presented voluntary apnea, and continued as soon as spontaneous breathing returned.

The intubation technique used in the experiment was performed blindly (without visualizing the glottis), as follows:

$1^{\text {st }}$ ) during anesthetic induction, the animal was positioned in dorsal decubitus, with extension of the head, and $0.1 \mathrm{ml}$ of lidocaine $1 \%$ was instilled as close as possible to the glottis of the animals; $\left.2^{\text {nd }}\right)$ the administration of isoflurane ${ }^{2}$ was maintained until it was found that the pedal withdrawal reflex had been lost, observed by interdigital pinching of the front limb. At this time, external palpation of the tracheal region was performed and the endotracheal tube was inserted without the 2.5-3.0 balloon, with a guide, orally, in the aditus larynx (Figure 2).

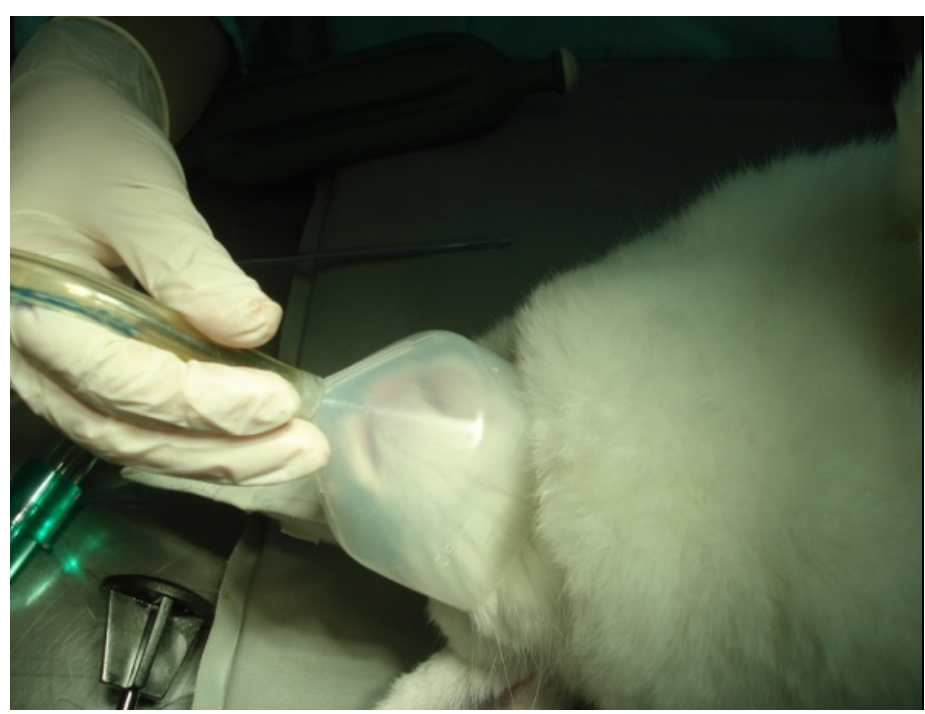

FIGURE 1 - Photograph showing the beginning of anesthetic induction using a face mask

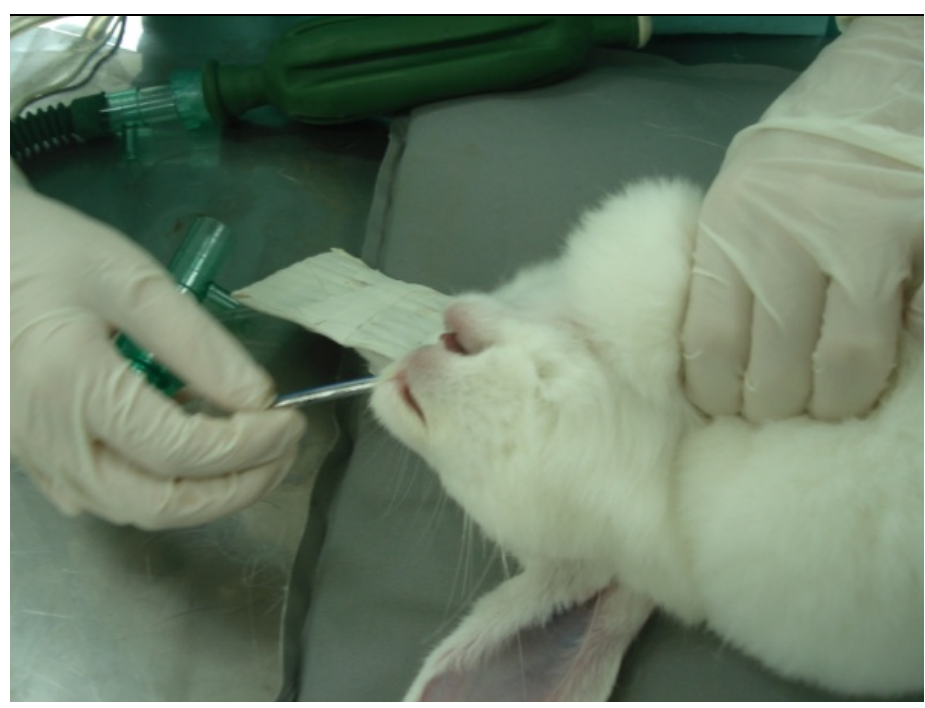

FIGURE 2 - Photograph of the external palpation of the tracheal region and the insertion of the endotracheal tube orally into the aditus larynx

$3^{\text {rd }}$ ) external palpation was used to occlude the esophagus and align the trachea with the larynx. Using the guide, pressure was maintained against the tongue of the animal, making it easier to guide the tube, which was introduced at a moment of inspiration, without forcing it against the larynx;

$\left.4^{\text {th }}\right)$ after this intubation was confirmed by palpating a single tubular structure at the level of the trachea (Figure 3) and not two (trachea and esophageal tube) by audible expiration in the tube, and by viewing the capnometry curve. Besides these signals, the cough reflexes and crossing of front limbs was very commonly observed (Figure 4). 


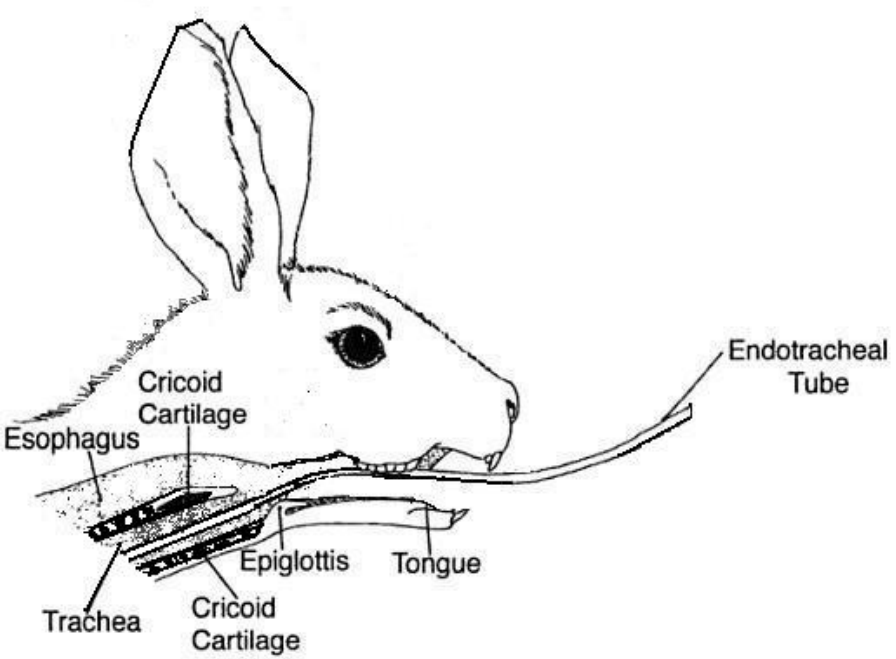

FIGURE 3 - Drawing of the tracheal anatomy of the rabbit, with the endotracheal tube in relation to the esophagus

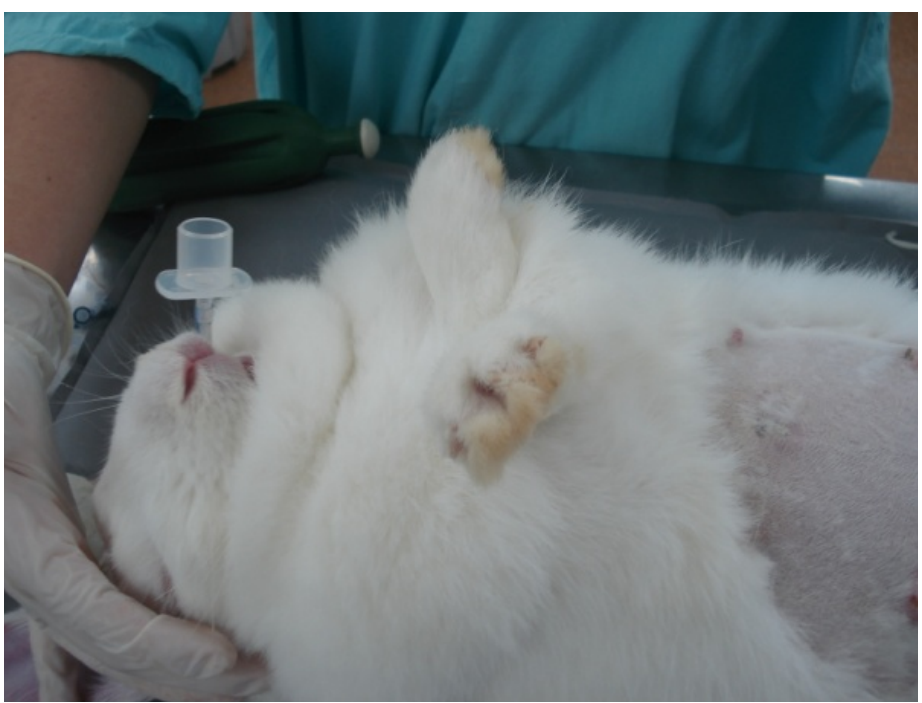

FIGURE 4 - Photograph of the confirmation of intubation with crossed front limbs

$\left.5^{\text {th }}\right)$ once the correct intubation was confirmed, the endotracheal tube was fixed and connected to the Takaoka anesthetic apparatus (Nikkei 2700), by means of a Baraka system.

The anesthetic plan was maintained with isofluorate $3-4 \%{ }^{2}$ under spontaneous ventilation, and manual ventilation was performed whenever necessary in order to keep capnometry (End-tidal Carbon Dioxide - ETCO ${ }_{2}$ ) between 35-45 mmHg. In order to maintain heart rate $<250 \mathrm{bpm}$, phentanyl was administered I.V. $(7.4 \mathrm{ug} / \mathrm{kg})^{1}$. Antibiotic therapy was performed with enrofloxacine IM $(5 \mathrm{mg} / \mathrm{kg})^{1}$.

The anesthetic monitoring was performed using an S/5TM (Datex- Ohmeda, GEMedical Systemf) multiparameter monitor, observing heart and respiratory rate, capnometry and oxymetry. In addition, a pediatric stethoscope was used on the animal to follow the heart rate and rhythm. The rabbits were kept on a thermal mattress and the rectal temperature was controlled.
After the anesthetist said the animal was ready, it was fixed on an operating table, placed on a heated mattress, the cautery plate was fixed, antisepsis was performed with polvedine and sterile drapes. the rabbits.

Standardized laparoscopic surgery was performed on all

Finalizing the surgical procedure, the pneumoperitoneum was gradually undone, the skin and abdominal wall were infiltrated at the site of the trochar portals with bupivacaine $(1.0 \mathrm{mg} / \mathrm{kg})^{1}$, and the administration of isoflurane was interrupted. The animals were kept intubated and on oxygen until they presented cough and swallowing reflexes. After extubation, the oxymetry was still monitored to make sure that the animal was breathing adequately.

The animals were kept in a warm place until recovery from the prone position. For postoperative analgesia, tramadol SC $(2 \mathrm{mg} / \mathrm{kg})$ was administered, and repeated after 24 hours ${ }^{1}$.

Daily postoperative care was maintained: acceptance of diet, body temperature, evaluation of behavior and checking the surgical wound to continue the initial study.

The quantitative variables were described by mean and standard deviation.

\section{Results}

No animal was lost, and no endotracheal trauma occurred in the 33 animals submitted to the anesthetic protocol and to the intubation technique without visualizing the trachea.

The mean values and standard deviation of the vital parameters of the animals can be seen in Table 1:

TABLE 1 - Vital and surgical parameters

\begin{tabular}{lcc}
\hline Variável & Mean & SD* \\
\hline HR (bpm) & 223.8 & 15.61 \\
RR (mpm) & 35 & 9 \\
Oxymetry (\%) & 96.94 & 0.99 \\
Capnometry (mmHg) & 42.82 & 4.02 \\
Pneumoperitoneum†(min) & 16.7 & 4.3 \\
Observation time† (min) & $01: 14$ & 8.52 \\
\hline
\end{tabular}

\section{Note:}

* $\mathrm{SD}=$ standard deviation

$\dagger$ Pneumoperitoneum $=$ mean time of surgery measured in minutes $\$$ Observation time $=$ mean time of observation from induction to recovery from anesthesia measured in minutes.

All the animals were intubated in at most three attempts, with a mean of two attempts per animal.

During surgery, the $\mathrm{SpO}_{2}$ diminished (Figure 5), due to the increased intraabdominal pressure caused by the pneumoperitoneum. Apnea during surgery was compensated with manual ventilation by the anesthetist, maintaining oxymetry at tolerable safety levels. 


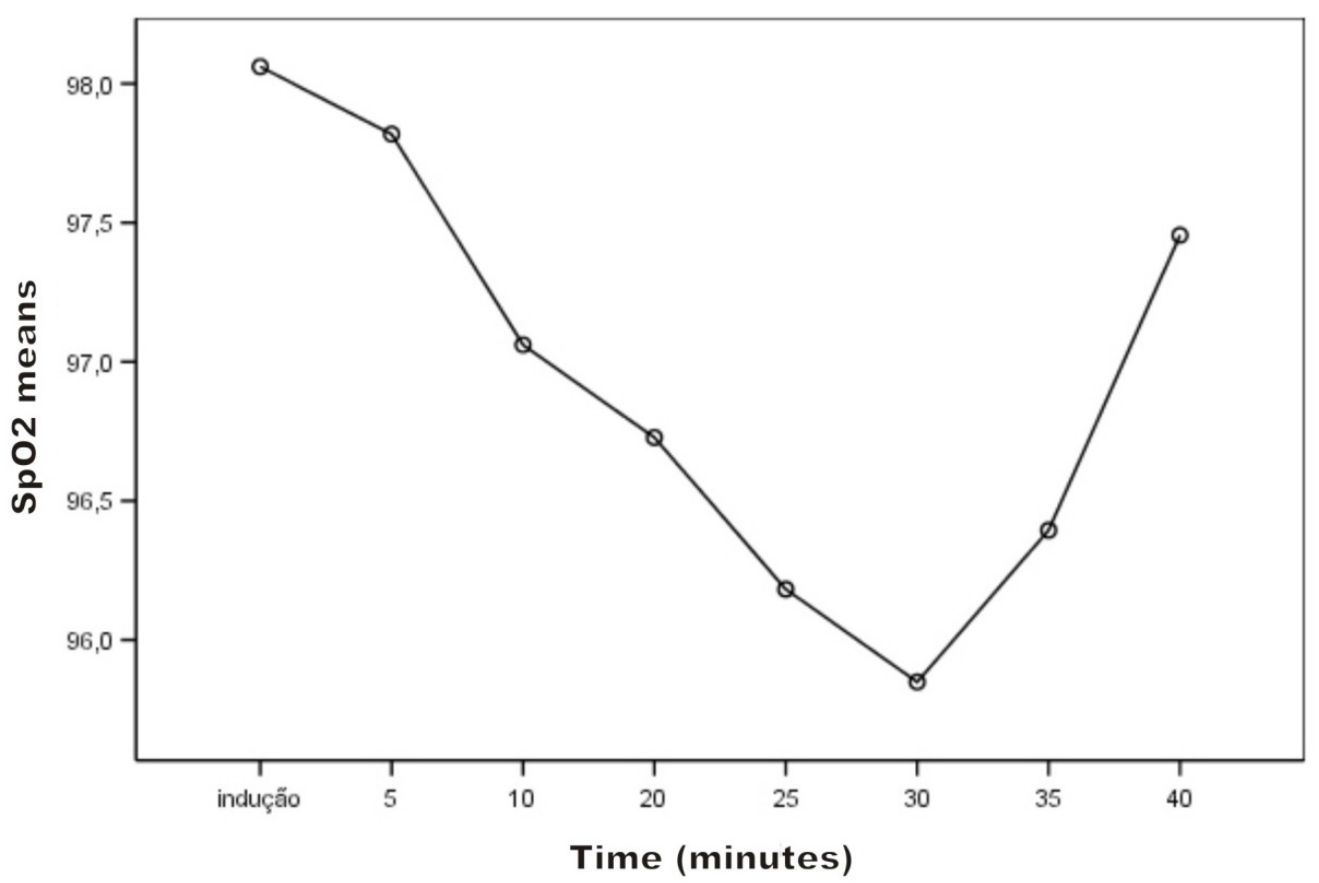

FIGURE 5 - O2 (\%) saturation in hemoglobin ( $\mathrm{SpO} 2)$, according to the time of observation: from induction to recovery from anesthesia

Likewise, the $\mathrm{ETCO}_{2}$ (Figure 6) increased, as a result of more $\mathrm{CO}_{2}$ absorption and reduction of ventilation, which was compensated by manual ventilation performed by the anesthetist.

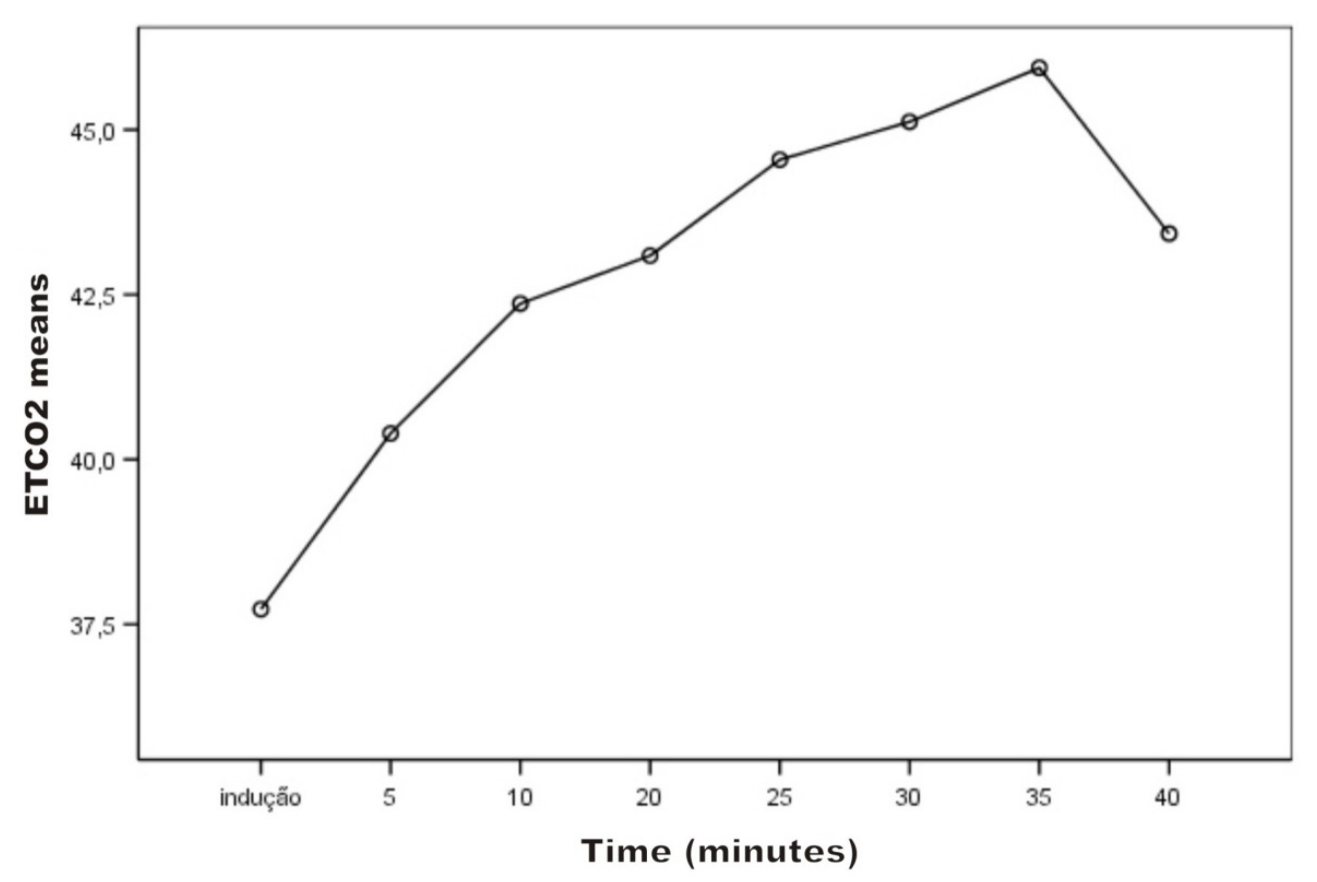

FIGURA 6 - Partial pressure of $\mathrm{CO} 2$, at the end of expiration (ETCO2), according to observation time: from induction to recovery from anesthesia 


\section{Discussion}

Rabbits are considered the laboratory animal which is most difficult to anesthetize ${ }^{1-5}$ and, therefore, a safe, easily performed protocol was chosen. The availability of drugs at the research site was also considered.

The choice of two tranquilizers that promote sedation in rabbits (acepromazine and midazolam) and an opioid (meperidine) enabled performing balanced anesthesia, using low doses of each drug. On using a balanced anesthesia protocol, the doses of each anesthetic agent may be relatively diminished, reducing the risk of an overdose and minimizing the side effects of each drug ${ }^{1,2,9}$.

Neuroleptoanalgesia is the state of sedation and analgesia caused by the combination of a tranquilizer (neuroleptic) and a narcotic. Although the animal remains conscious and responds to certain stimuli, several manipulations can be performed ${ }^{1}$, such as shaving, venous access and induction with isoflurane, with the less stressful use of a face mask ${ }^{2,10}$.

No atropine was administered to the rabbits, since none of them presented bradycardia or excessive salivation and bronchial secretion. Besides, more than $50 \%$ of the rabbits produce atrophinesterase which degrades and inactivates atropine ${ }^{1,2}$.

Isoflurane is the inhalatory agent of choice in many experimental surgery laboratories, and its advantages are cardiac safety, quick induction and recovery, minimal hepatic metabolization, and reduced viscerotoxicity ${ }^{1,2}$. There are disadvantages as to costs, hypotension and respiratory changes ${ }^{1,2,10}$.

In rabbits, induction can be performed with a volatile anesthetic by face mask, but a sedative must be administered previously, since it is a very stressful procedure for the animal. Even sedated, rabbits present apnea in response to the irritative effect of isoflurane. During induction, the animal was carefully observed, and the mask removed if respiratory block occurred ${ }^{1}$.

The larynx can be instilled with local anesthetic, before intubation, to minimize the risk of laryngospasm ${ }^{1,5}$.

Great care must be taken to avoid pushing the endotracheal tube against the larynx, since the structure is delicate and easily injured. The consequent postoperative edema and hemorrhage may cause respiratory obstruction and death ${ }^{5}$.

Intubation can be performed with or without direct viewing of the larynx in ventral or dorsal decubitus. For successful intubation, the mouth, larynx and trachea must be aligned ${ }^{5}$.
No rabbits were lost, and there were no endotracheal traumas in the 33 animals submitted to the anesthesia protocol and to the intubation technique without visualizing the trachea.

\section{Conclusion}

This protocol proved adequate for anesthetizing rabbits in experimental videolaparoscopic surgery, and tracheal intubation guided by external palpation is easy to perform and can be done with minimal trauma to the trachea.

\section{References}

1. Cornell institutional Animal Care and Use Committee (IACUC) and tje Cornell Center for Animal Resources and Education(CARE). Disponível em $<$ http://www.research.cornell.edu/care/documents/SOPs/CARE103.pdf $>$. Acesso em: 07 set. 2009

2. Fonseca NM, Goldenberg S, Eurides D, Novo NF, Lima CAP. Avaliação de um novo sistema circular de anestesia: anestesia quantitativa com isuflorane em coelhos. Acta Cir Bras. 1997;12(4):240-5.

3. Kallas E, Schnaider TB, Juliano Y, Novo NF, Kallas IE, Engelman MFB, Kallas AC, Castro LF. Anesthesia model in rabbits for thoracic surgery. Acta Cir Bras. 2001;16(2):91-6.

4. Worthley SG, Roque M, Helft G, Soundararajan K, Siddiqui M, Reis ED. Rapid oral endotracheal intubation with a fibre-optic scope in rabbits: a simple and reliable technique. Lab Anim Sci. 2000;34:199-201.

5. Morgan TJ, Glowaski MM. Teaching a new method of rabbit intubation. Lab Anim Sci. 2007;46:32-6.

6. Guide for the care and use of laboratory animals. In: Institute of laboratory animal research. National Research Council: Whashington DC; 1996.

7. Lipman NS, Marini RP, Erdman SE. Comparison of ketamine/xylazine and ketamine/xylazine and ketamine/sylazine/acepromazine anesthesia in the rabbit. Lab Anim Sci. 1990;40:395-8.

8. Rosa Junior A, Trindade MRM, Shemes TF, Tavares WC. Influência da abordagem cirúrgica (videolaparoscopia versus laparotomia) na gestação de coelhas prenhas. Acta Cir Bras. 2003;18(4):337-41.

9. Lipman NS, Marini RP, Erdman SE. Comparison of ketamine/xylazine and ketamine/xylazine and ketamine/sylazine/acepromazine anesthesia in the rabbit. Lab Anim Sci. 1990;40:395-8.

10. Hedenqvist P, Roughan JV, Antunes L, Orr H, Flecknell PA. Induction of anasesthesia with desflurane and isoflurane in the rabbit. Lab Anim. 2001;35:172-9.

\section{Correspondence:}

Rosi Pereira Balbinotto

Rua Lucas de Oliveira, 909/803

90440-011 - Porto Alegre - RS - Brazil

Phone: (55 51)3333-3364

rosi.balbinotto@terra..com

Conflict of interest: none Financial source: FIPE at HCPA

Received: August 10, 2009

Review: October 14, 2009

Accepted: November 12, 2009

\section{How to cite this article}

Balbinotto RP, Trindade MRM, Meyer FM, Rosa Junior A, Muller ALL, Nunes AG, Silva R. Anesthetic protocol for videolaparoscopic surgery in rabbits. Acta Cir Bras. [serial on the Internet] 2010 Jan-Feb;25(1). Available from URL: http://www.scielo.br/acb 